\title{
AVALIAÇÃO DA RESPOSTA GLICÊMICA AO CONSUMO DE CASCA DE TUCUMÃ-DA- AMAZÔNIA (Astrocaryum aculeatum) EM MODELO EXPERIMENTAL DE OBESIDADE.
}

\author{
Camila S. Leal ${ }^{\star}$, Verena S. Lima, Mario R. M. Junior.
}

\section{Resumo}

O tucumã-da-Amazônia (Astrocaryum aculeatum) é uma fruta nativa da região amazônica com potencial agroeconômico e biológico pouco explorado, portanto, o estudo da aplicação deste fruto, no controle da obesidade e suas doenças associadas, é oportuno. Assim, o trabalho em questão visou aplicar o consumo da casca de tucumã-da- Amazônia (Astrocaryum aculeatum) em modelo experimental alimentado com dieta indutora de obesidade a fim de avaliar controle nos parâmetros glicêmicos. Para tanto, a casca do tucumã-da-Amazônia foi submetida à liofilização, avaliados seus macronutrientes, e então foi incorporada às dietas normolipídica e hiperlipídica para realização de ensaio biológico em camundongos. Foram coletados dados de ganho de peso e consumo alimentar para posterior análise, e realizadas avaliações de sensibilidade à glicose e à insulina. A casca de tucumã-da-Amazônia se mostrou eficiente no controle de ganho de peso, contudo não foi possível observar alterações na resposta insulinêmica. Outras análises são necessárias para maiores conclusões do potencial da matriz estudada no controle da obesidade e suas complicações.

Palavras-chave: Obesidade, resistência à insulina, fitoquímicos.

\section{Introdução}

A obesidade é uma pandemia caracterizada pela inflamação crônica e impacto negativo em todo o organismo. Assim, pesquisas vêm buscando alternativas para controlar e/ou minimizar os efeitos dessa doença e de suas comorbidades, como a utilização de alimentos funcionais1. Pesquisas revelam que o tucumã-daAmazônia (Astrocaryum aculeatum), conta com um grande número de compostos bioativos que possuem reconhecida ação antioxidante, antiobesogênica e hipoglicêmica. Portanto, o estudo da aplicação deste fruto, no controle da obesidade e suas doenças associadas, é oportuno. Deste modo, o escopo deste trabalho foi avaliar a capacidade da casca do tucumãda-Amazônia na prevenção de eventos fisiopatológicos relacionados ao controle glicêmico.

\section{Resultados e Discussão}

A casca de tucumã foi liofilizada, obtendo um rendimento de $36,10 \%$ e composição centesimal apresentada na Figura 1:

Figura 1. Composição centesimal casca de tucumã liofilizada $(C T L)$.

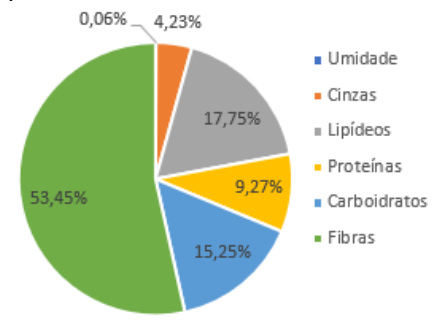

Foi realizado ensaio biológico com 40 camundongos machos C57BL/6 adquiridos no CEMIB/ Unicamp. Os animais foram randomizados e mantidos em dupla, com temperatura $\left(22 \pm 1^{\circ} \mathrm{C}\right)$ e umidade do ar controlado (60$70 \%$ ) e ciclo claro/escuro de 12 horas durante 14 semanas. Cada grupo foi separado de acordo com a dieta recebida: controle normolipídico (CN), normolipídico com casca de tucumã (NCT), controle hiperlipídico $(\mathrm{CH})$ e hiperlipídico com casca de tucumã (HCT). As dietas experimentais com CTL receberam $8 \%$ da mesma. Os resulados obtidos durante o ensaio biológico indicaram ganho de peso, índice de massa corporal (IMC), Índice de Lee, taxa especifica de ganho de peso (TAE), e coeficiente de ganho de peso por consumo alimentar (CGPCA) estatisticamente semelhantes entre os grupo normolipídico e hiperlipídico que tiveram sua dieta incorporada com casca de tucumã.

Quanto à resistência à glicose (GTT) e à insulina (ITT) (Figura 2), os animais alimentados com dieta normolipídica tiveram redução na glicemia, comparados aos de dietas hiperlipídicas, contudo não se observou diferença estatística significativa entre os grupos quanto às tolerâncias glicêmica e insulinêmica.

Figura 2. Curva glicêmica dos grupos experimentais, pelo teste GTT e ITT
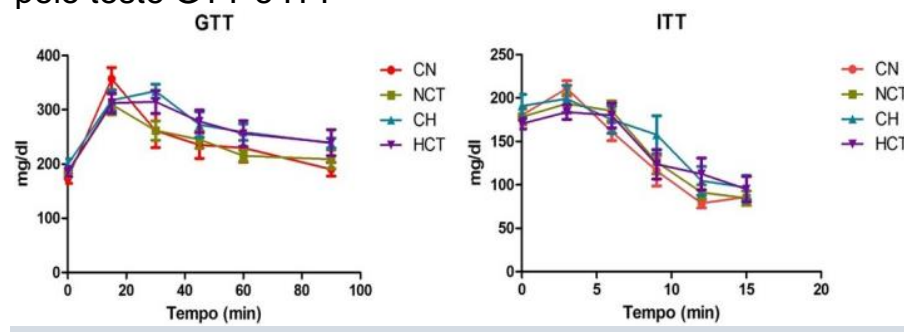

\section{Conclusões}

Todos os grupos obtiveram crescimento satisfatório, sendo observado controle no ganho de peso dos animais que tiveram sua dieta incorporada com casca de tucumã. Contudo, não foi possível detectar diferenças metabólicas significativas referentes ao controle glicêmico entre os grupos com e sem consumo da casca de Tucumã-daAmazônia.

\section{Agradecimentos}

Agradeço à FAPESP pelo financiamento do projeto de Iniciação Científica.

${ }^{1}$ Freitas, M. C. et al. Resistência à insulina associado à obesidade: Efeitos antiinflamatórios do exercício físico. R. Bras. Ci. e Mov. 2014; 22(3): 139-147. 